\title{
Determinants of medical students' empathy during clinical rotation
}

\author{
Resiana Citra ${ }^{1}$, Rizma Adlia Syakurah ${ }^{2}$, Eddy Roflin ${ }^{3}$ \\ ${ }^{1,3}$ Faculty of Medicine, Sriwijaya University, Indonesia \\ ${ }^{2}$ Public Health Faculty, Sriwijaya University, Indonesia
}

\section{Article Info \\ Article history: \\ Revised May 11, 2021 \\ Accepted Jun 18, 2021 \\ Keywords: \\ Empathy \\ Ethical standard \\ Medical students \\ Patient \\ Personality \\ Professionalism}

Received Nov 20, 2020

\begin{abstract}
Medical students in clinical rotation level have been developed comprehension and implementation of empathy, considering that they have already dealt with patients in the first hand, whereas professionalism and ethics are two main competences as a physician. This study aims to discuss and investigates determinants of medical students' empathy towards their patients during clinical rotation in the hospital. A qualitative study with phenomenology approach using focus group discussion (FGD) was accompanied with an open-ended questionnaire to serve as preliminary data and basis of FGD topic guidelines involved fourth and fifth grade medical students that has to pass one and/or two of these stages out of the 15 stages in clinical rotation. As much 191 students participated of the written questionnaire and 28 students agree upon voluntarily joining the FGD, which is held with a snowball sampling approach and finishes in five batches. The three main determinants are: i) Internal factors: knowledge about the importance of empathy, direct experience, personality, motivation, mood (emotion), and personal experience; ii) Patient's and patient's family factors: patient's attitudes, patient's family's attitudes, patient's socioeconomic status, patient's illness type and severity; and iii) Environment factors: burnout, satisfaction or appreciation in the job, work environment, and role models. Many factors influence medical students in expressing and implementing empathy as they are taught to do to their patients. Medical school as an institution responsible for upholding the professionalism and ethical standard can help to create more suitable environment for the students to ensure maximum learning experience.
\end{abstract}

This is an open access article under the CC BY-SA license.

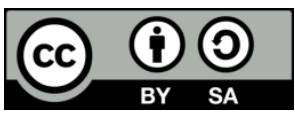

\section{Corresponding Author:}

Rizma Adlia Syakurah

Public Health Faculty

Sriwijaya University

Jl. Raya Palembang-Prabumulih KM. 32 Indralaya, Ogan Ilir, South Sumatera, 30662, Indonesia

Email: rizma.syakurah@gmail.com

\section{INTRODUCTION}

Empathy is a complex concept and often described as to feel what others are felt, to imagine oneself in others' position, understanding others' thought, as a basis to response others suffering [1]. Empathy is also defined as multidimensional concept that covers cognitive, emotion, morale, and attitude dimension [2], [3]. Therefore, defining empathy means meeting one and/or more of these four dimensions. The different definition of empathy occurs due to the lacking consensus or agreement on empathy meaning in the literatures of empathy [4]. 
In the medical field, empathy is understood as a doctor's cognitive (not only emotional) skill which involves caring, understanding experience, worry, and patient's perspective, then relates it to communication skill [5]. Doctor's empathy towards patients gives positive affection to the patient's condition, for example increasing diagnostic accuracy, understanding the disease condition, obedience towards medication, increasing patient's satisfaction and life quality, establishing a sense of patient's comfort and trust to the doctor, also decreasing malpractice claim and medical errors [6]-[9].

Medical students' empathy has changed oftentimes and researched in some countries oftentimes. It can be found that the level of study of medical education taken by the students is in accordance with their empathy level, since the deeper of medical science mastery and many practices that involve interaction with the patients [9]. However, this matter cannot be generalized, because there are findings that interaction with the patients also can decrease empathy [10]. Moreover, empathy of medical students is also decreasing during their study [11]-[13].

Through the medical education, the empathy should grow for medical students, especially when they have experience in taking care the patients, and thus they become competent. Throughout their learning experience as medical students, especially in clinical rotation level, medical students' comprehension and implementation of empathy have been developed, considering that they have already dealt with patients in the first hand, whereas professionalism and ethics are two main competences as a physician. However, the inconsistency of findings raises a question of what determinants of empathy implementation in medical students during their clinical rotation are, especially in a collectivist culture like Indonesia. Thus, faculty of medicine as an educational institution needs to provide ample space and time for the students to be able to apply their knowledge in an ideal manner, to practice by themselves and to show empathy well. The answer to this question can serve as a valuable feedback in increasing the quality of medical education system for the students. This research focused on exploring factor that affects the empathy of medical students who take professional education in Indonesia. The same research had been done in Germany that explored empathy within the cause of change of medical students' empathy [14], [15].

\section{RESEARCH METHOD}

A qualitative interpretive case study was conducted at the Faculty of Medicine, X University in Indonesia from August to November 2019. The study uses a phenomenology approach to see and understand the meaning of direct experience under certain phenomena. The subjects are students of Medical Professional Education of Faculty of Medicine, X University, that has to passed one and/or two of these stages out of the 15 stages. The researchers assumed their stage has required frequent direct contacts with the patients, as doctors in general. The subjects are chosen by a purposive method, using an open-ended questionnaire with Google Form as shown in Table 1. A pilot open-ended questionnaire is carried out with 10 participants of the 2014 and 2015 doctor professional education. The sample size is not fixed, and then the open-ended questionnaire is closed after the answers collected are saturated. The results of this open-ended questionnaire are used as the guideline in considering the participants and formulating the topics in FGD as shown in Table 2.

There are 28 students who become FGD participants to be conducted at the Faculty of Medicine, X University, with eight participants per session, and nobody has backed out. The FGD Participants are divided based on the number of stages that they have gone through and their grades of study. There are only researcher and participants and it is guided by a moderator and attended by a note taker for 45-60 minutes. The FGD uses an audio recorder and notes as the device to collect data by asking participants' permission. The FGD is completed in a single session and not repeated. Data transcripts are not sent to the participants, but data credibility is carried out using triangulation of techniques and sources, member checks, and reference material from FGD records, photographs and other authentic documents.

The data are coding begins early after the first discussion and the second coding is done by categorizing the data. The last coding is done to describe empathy change and the factors affecting such empathy. Data transcript is collected and then becomes a sub-theme. The data transcript is managed by Microsoft Office Word software ver.2010, and the manual analysis is done as needed. Participant quotations presented to illustrate the findings are used to maintain anonymity. The determinants discussed often appear during the data collection process, so the main theme is not clearly presented.

The objectives and purpose of the study, and things that are necessary regarding data respondents are notified in advance by informed consent. Participants are given the option of their availability to voluntarily discuss the research topic in the form of focus group discussions. Participants are entitled to refuse or resign during the research process without any fine or sanctions. This research was approved by Faculty of Medicine Sriwijaya University (No.1172/UN9.FK/TU.SB5/2019). 
Table 1. Questions in open-ended questionnaire

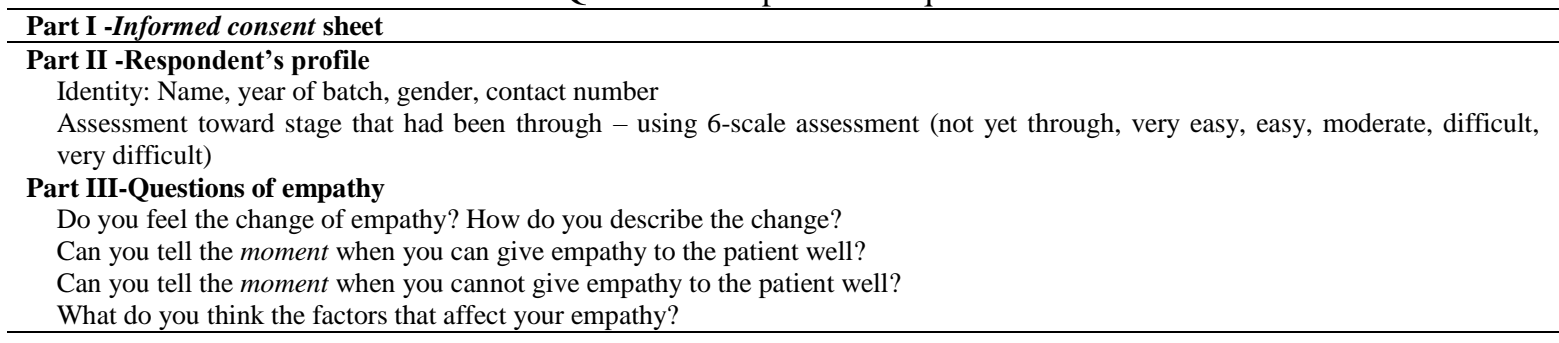

Table 2. FGD guidelines

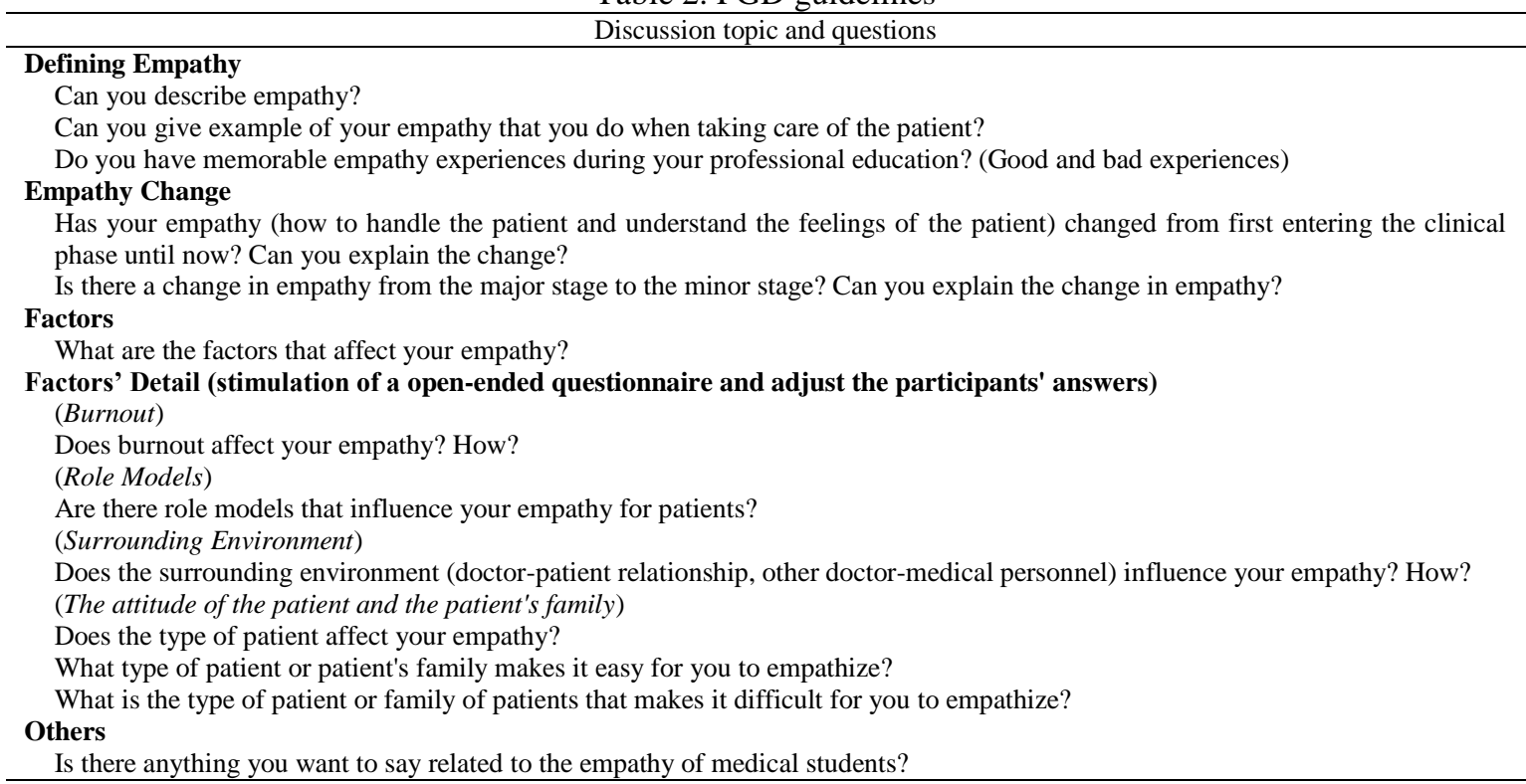

\section{RESULTS AND DISCUSSION}

The participants who answer the open-ended questionnaire consist of male (70\%) and female (30\%), and are from batch of $2014(58 \%)$ and 2015 (42\%). For data collection through FGD, the researchers determine the condition of having passed one and/or two of these stages (of 15 stages) with the expectation of participants who have already obtained an overview of the medical profession education life. The total 191 responses from the first stage of open-ended questionnaire as well as the 28 medical students as informants who are divided into five batches of focus group discussions are voluntarily recruited through the written consents beforehand.

\subsection{Empathy change}

When asked about whether they feel there is a change in empathy during their clinical rotation, the results of the open-ended questionnaire show that there is a change in empathy experienced by medical students with varying perceptions as shown in Figure 1.

The majority of participants $(50 \%)$ answers that the empathy they feel, in general, is increasing. Other patterns include empathy depending on the mood or emotion being felt (27\%), generally decreasing $(9 \%)$, and others. However, when conducting further exploration in FGD, the students express empathy that they feel in fluctuation, depending on certain factors and situations and conditions, but tend to decrease more.

"There are many factors... So it cannot be said one (principal factor), (they are) really merged. From oneself, environment, and patient and situation..."-FGD A

" (It is) Multifactorial. When the mood is good, feeling expert, feeling enjoy. But when it is not good, it decreases our mood to the patients." - FGD D

"..before entering Faculty of Medicine, we were still white, [we thought] "why are doctors like this" (negative). After we enter.. it is true. I felt it myself...we try to survive too, so be it.. What's important is passing...[the stages]." -FGD E 


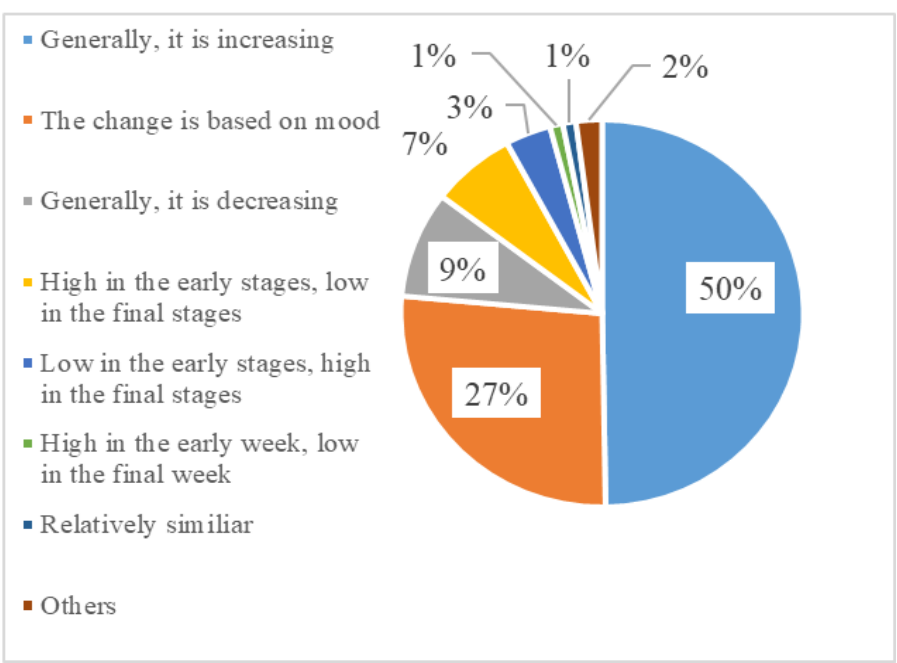

Figure 1. Variation perception of empathy change

\subsection{Factors affecting empathy}

Three main factors with 14 sub-topics identified as factors that affect empathy of medical students towards patients are taken from the focus group discussion result as shown Table 3.

Table 3. Factors that affect the empathy of medical students towards patients

\begin{tabular}{ll}
\hline \multicolumn{1}{c}{ Internal-factor } & \multicolumn{1}{c}{ Knowledge about the importance of empathy } \\
\hline & Direct experience \\
& Personality \\
& Emotion (Mood) \\
& Motivation \\
& Similarity/personal experience \\
& Patient's attitude \\
Patients' and patients' family's & Patient's family attitude \\
factor & Patient's Socio-economy \\
& Type and degree of disease severity \\
& Burnout \\
Work environment factor & Surrounding environment \\
& Satisfactory/job appreciation \\
& Role models \\
\hline
\end{tabular}

\subsubsection{Internal-factor}

The main factor influencing empathy according to participants is the students themselves.

"I personally felt (the factor is) from MYSELF!...if you have high self-awareness about empathy to the patient, aware [also] about professionalism to patients.. You'll be good to them." - R, Female, 2015, Written Interview

Understanding the importance of empathy can help students empathize more to the patients. With this being understood, students will try to provide the best service for patients, not only limited to providing treatment but also to providing support in the form of care and empathy.

"...if we have empathy we can also give support or the education that we give to the patient will be meaningful [because] we understand how the patients are...."-A5, Female, FGD A

"Everybody needs empathy, it is what makes you still human, it is the human nature, if you don't have empathy you don't think about how to be a patient... If empathize, they should think this somebody loves one so I have to help. " - D2, Female, FGD D

This understanding of the importance of empathy is also supported by the reality in the field that they witness first-hand the benefits of empathy and the impact of not being able to show empathy well to patients. 
Interaction with patients directly can foster empathy because students can clearly see what patients are complaining about so they can easily think and feel what the patients have experienced and felt.

“... In this area, we do the job, who report about the patients, because those are our patients, so we feel guilty when he gets worse.”-B2, Female, FGD

Unfortunately, contacts with patients that can foster empathy are hampered by the students' lack of time and opportunity to interact with the patients.

“...because of lack of time and a lot of work. Time is not directly proportional to the workload..." -A3, Female, FGD A

"On the ward..we have longer time for bonding with the patients...the patients are few, so with 1-hour duration....could be more comfortable asking questions.. so the empathy is more [increasing]. While the patients are many, it looks like that [we are] only working [and] without empathy." -D1, Female, FGD D

However, apparently, continuous contacts with patients can also reduce empathy. One example is often seeing patients with a high degree of severity, so that when getting a case with a lighter one, students will appear less empathy.

“Because it's already too often so it's normal...." -B4, Female, FGD B

"...the patient wants wart surgery..but he was hysterically afraid that she might be in her the first surgery. After that the doctor said, "it is only a small thing ma'am, a lot of my patient are worse," it showed non-empathical toward the patient...., if the experience is more, so the empathy is like that [decreasing]. Moreover, when the case is easy...."-D1, Female, FGD D

Personality also affects empathy, for example an apathetic person will tend to be difficult to show empathy well. The person who is friendly and likes to help others will easily show empathy to others.

"There was one experience, the patient was passed away, and honestly, I was just trying to take action as the SOP without giving empathy to the patient's family which were panicking and crying in front of me" - J, Female, 2014, Written Interview

"...I might really don't have a heart. My first plus [died] patient was my aunt, then it felt so-so (flat expression)" -B2, Female, FGD B

"My empathy was decreasing to them (friends or others) [but] it did not affect the empathy to my patient...So when I am tired, tomorrow has an exam..I am just trying to [keep] give the best." -A5, Male FGD A

Another factor that affects the empathy of medical students towards patients is self-motivation.

"Sometimes we wanted to empathize depending on what was the motivation, if you wanted to be a real doctor you must be thinking about the patient, if just passing by, may be you wanted to be in the structural [position in the hospital] and something like that, no need to think about the patient. So you just want to be graduated.. "-D2, Female, FGD D

The lack of empathy for patients felt by the students can also just be temporary. Sometimes a negative mood or a personal event can inhibit empathic behaviour.

"I was having bad mood, so I became ignorant"-F, Male, 2015, Written Interview

"While having issues, the empathy is decreasing sometimes"-R, Male, 2014, Written Interview

"Everybody has limit. Some people might be in the limit, so they just wanted to finish the day ASAP, maybe next days they are energetic." -D3, Male, FGD D

Medical students who have ever experienced what is felt by the patient or the patient's family can also affect empathy for patients. They will tend to empathize easier for patients with similar experiences.

"When the patient disease was the same with the disease that my family suffered [I could easier to empathize].”-T, Male, 2014, Written Interview

".. one that can increase empathy is... personal experience, because I had fractured, and I was treated and how it felt, so, me and my fractured patients are tended to care..”-A1, Male FGD A 
"My father got stroke, so during the stage of neurology, I gave my best.. [toward the patient] I was more RJP.. [because] I stood at their shoes..." -D2, Female, FGD D

\subsubsection{Patient's and patient's family's factor}

The patient's attitude affects the empathy of medical students. The attitudes of patients which can increase empathy are cooperative, friendly, and open. The attitude which is difficult to show empathy is seen when patients are not polite, complain a lot, or think that they know better than their doctor.

"If the patient and family trust and listen also do the suggestion and the action that is given, [I can show my empathy well].”-R, Female, 2015, Written Interview

"....the patient is so dependent, I think in other terms are annoying, stubborn... made a call every second, however the matter was not urgent... sometimes this easy case and annoyance that decrease my empathy, which made me "who cares" made me ignorant sometimes..." -A5, Male, FGD A

In addition to patients' attitude, the factor that affects empathy toward patient is patients' family's attitude. It is because the patient's family often interacts with the medical students so it will affect the empathy towards patients.

"Actually, sometimes, it was not in-empathy towards patients. But the family who look after the patients. They sometimes did not appreciate us." -T, Female, 2014, Written Interview

The patient's family's attitudes include attitudes that can increase empathy such as being polite, entrusting actions to the doctor, being friendly, and being cooperative. On the contrary, these make them tend to work half-heartedly and difficult to show empathy to patients.

"[Cannot show empathy well] if the patients and families were rude by expecting co-assistant [medical students] to be a "servant"... and they asked impolitely.. "-E, Female, 2014, Written Interview

“..the family was not friendly so [we were like] half-heartedly work..." -D1, Female, FGD D

Poor attitude of the patient or patient's family adversely affects the quality of health services provided.

“..since then, my empathy was decreasing...I asked my junior [to give check up]”-A2, Female, FGD A

"...in the end was all co-ass did not want to enter the room..of course, who else who wanted to treat a patient like that one.." -E2, Male, FGD E

Patients who show power tend to make medical students less empathic with them, in contrast to socioeconomically lower patients who make it easier for students to empathize.

"When the patient assumed that the doctor cannot understand him and do nothing, so the patient shows the character and position of him [which was hard to empathize]." -P, Female, 2014, Written Interview "Our empathy arise [when] there are some problems out of health.especially such aseconomic, family supports, such those matters."-A4, Male, FGD A

Another thing that affects empathy depends on the type and degree of disease severity of the patient. Disease types include subjects who suffer, such as pediatric patients or elderly patients and the type of illnesses suffered, such as mental patients or obstetry-gynecology patients. The severity, for example, is for the patients with mild or moderate cases in terminal phase.

"[more empathic] when the patients were elder but there was no family escorting the elder to check up... "-T, Female, 2014, Written Interview

"in the psychiatry, it is such gentle talk to the patient, they ask with patience, no [rising voice].." -D3, Male, FGD D

"[I got]alcohol intoxication patients, imagine that civet coffee were mixed with autan (anti mosquito lotion), just to make them "fly". It was stupid, annoying... just this patient. Of course, I'm upset. How can I being empatethic..." -C5, Male, FGD C

\subsubsection{Work environment factor}

Burnout becomes the biggest factor in affecting medical students' empathy towards patients. It comes from academic burden, work burden, even harassment or bullying the students have experienced. Such burnout makes empathy decrease. 
“When ... many scientific assignments or others sometimes I forget to empathize the patients." -F, Male, 2014, Written Interview

“.. mostly in tired condition, many assignments, in charge, case report had not been written, patient's family sometimes asked that we answered less...”-A1, Male, FGD A

In addition to the academic burden that causes burnout, much workload is also one of the factors that influence empathy.

“...In busy times and asked by senior to check all patients fast. Automatically we only keeping on fast pace by only asking short complaints, checking vital sign (just like that)......-C, Male, 2014, Written Interview

"If one patient's follow up per hour or two, it is... for example [somebody said] "hey, the patient is plus [died] " comes out 'finally it is plus'. Alhamdulillah." -B2, Female, FGD B

Burnout can also be because of harrasment or bullying. It may come from doctors, seniors, paramedics, or others.

"Patients are many but it is not (only) because of it, resident's order is tiring when they ask rudely... what is the mistake of asking politely. "-C5, Male, FGD C

Feeling appreciated can also increase students' empathy towards patients. On the contrary, when the work is not appreciated, it leads the medical student to be less empathic.

"I am sometimes touched that I do less but they thank me.. "-B4, Female, FGD B

"[We're] not appreciated... We give advice... But why they do not listen, nah. So..you ignore yourself, why do we care for you?!." -D2, Female, FGD D

Another factor is the condition of working environment. Students assess whether the condition of the hospital is conducive and supporting to be empathic or not; for example, how cooperative some parties are, what hospital regulation system is, and so on.

"If the situation is conducive, comfortable, and everybody working cooperatively.... it would raise empathy." -T, Female, 2014, Written Interview

"....check the poly.. maybe because of the system error, the regulation, so there are many factors can affect the empathy. Actually, we feel sorry for those who wait from morning until afternoon, just see the face, writing, then he comes back. It is not what the patients expected." -A5, Male, FGD A

The positive role model will give positive influence to the students so they can easily emphatize the patients.

"In my opinion, the good doctor is the one who empathize like doctor A. I was changed there...my paradigm about there was a doctor who $100 \%$ for patients, $100 \%$ for their students and $100 \%$ for family."-E2, 2015, FGD E

Positive role model is assumed by the medical students as a doctor who tries to give the best for the patients.

“.....after taking intern and anesteshiology stages, the empathy was decreasing. It was ordinary to see some parties underestimate the patients.....”- F, 2014, Written Interview

There is also a negative role model of a doctor who gives inappropriate example to the students' attitude toward the patients.

“.....after taking intern and anesteshiology stages, the empathy was decreasing. It was ordinary to see some parties underestimate the patients.....”- F, 2014, Written Interview

Consciously or not, the medical students imitate such role model behaviours.

"In my first day [co-ass] I also thought, "Why the resident and senior of 2013 the behavior was [angry, ignorant] to the patient, but I also think that I am like one.”-C1, Female, FGD C

"at first we do not have courage to snap the patients, and there was one who snapped the patients, at first we were shocked... by the time flies... we also become one [snapping]."-D3, Male, FGD D 


\subsection{Discussion}

Some determinants can increase the empathy of medical students, but at the same time it can also reduce their empathy. Sometimes one and/or more factors can influence one's empathy, but on the other hand one and/or more factors can have a different influence on others. In the research discussion, the determinants discussed are determinants that often appear during the data collection process.

Knowledge about empathy, such as the benefits of empathy, antipathy impacts, and ways to be empathetic can be one of the ways to increase empathy [16]. Direct contact experience with patients is one of the most influential ways in increasing the students' empathy because meeting the patients provides opportunities for direct learning and practices skills related to empathy, such as asking the right questions, learning the patient's body language, and showing empathy [4]. Unfortunately, the lack of time held by medical students prevents them from being empathic towards patients [17], [18]. Agreeable personality type and openness to experience can show more empathy [19]. However, other types cannot be justified that they are incapable of communicating and empathizing, therefore medical students must be equipped with the right knowledge and skills to understand patients [20]. While, the changes in pre-clinical life and clinical clerkship are thought to an effect on personal well-being, especially a lack of rest time [21].

Characteristics of patient's and patient's family's attitudes affect the empathy of medical students because empathy is also related to communication. One of the communication skills that doctors must possess is being able to show empathy both verbally and nonverbally towards the patients [22]. There are various obstacles in the communication with patients or their families, for example their poor attitude, emotional factors they have, and their distrust of medical students which also make it difficult for the students to show empathy [23].

Burnout can come from various things, such as academic burden, work burden, or harassment and bullying experienced by the students. One kind of bullying the students experience is excessive work burden and influence on undermined confidence [24]. This harassment can also cause burnout. Burnout from whatever reason creates negative mood or emotion that is felt by the students [21]. Burnout is a stress-related syndrome, signed by fatigue, depersonalization and reduced achievement, and is associated with lower empathy of the students [25]. Burnout and empathy have a complex two-way relationship. On the other hand, there is evidence that well-being has a positive correlation with the level of empathy [26]. Thus, the implementation of regulations such as reducing work hours and providing seminars of self-development can be conducted to avoid burnout and to control emotion (moods) that can affect students' empathy [15], [27].

Role models have many roles in forming attitude, determining career, or giving affects to medical students in emphatizing the patients [28], [29], [30]. Medical students easily adopt their role model behaviour. Imitating someone shows that the observer aims at achieving the intention of the role model. As a result, the purpose of role model behaviour is more important than the behaviour itself, whether the behaviour is empathic or not towards the patient [31].

This research is the first qualitative research in Indonesia that explores the factors which influence the empathy of medical students towards patients. The most crucial research limitation in this research is the limited research participants, which are only medical professional students of X University with their cultural education that might be different, compared to that of other universities. Therefore, the results of this study do not represent all medical students. However, some of the results of this research resemble the results of similar studies conducted in several countries [14], [15], [32], [33]. The authorities need to evaluate regulations in the hospital, for example regarding working hours to avoid burnout which can affect the empathy of medical students, medical education institutions need to hold positive activities such as selfdevelopment seminars to develop personalities and efforts to regulate students' emotions (moods) which can affect the empathy of medical students towards patients.

\section{CONCLUSION}

This research focused on exploring factor that affects the empathy of medical students who take professional education in Indonesia. The finding of this study is various factors can influence medical students in showing empathy towards patients, such as internal-factor, patients' and patients' family's factor, and work environment factor. These factors are personal, which mean that some factors can affect the empathy of an individual, but, on the other hand do not affect that of other individuals. The authorities need to evaluate regulations in the hospital and medical education institutions need to hold positive activities to develop personalities and efforts to regulate students' emotions (moods).

\section{REFERENCES}

[1] Decety J., and Svetlova M., "Putting together phylogenetic and ontogenetic perspectives on empathy," Developmental cognitive neuroscience, vol. 2, no. 1, pp. 1-24, 2012, doi: 10.1016/j.dcn.2011.05.003. 
[2] Cuff B. M., Brown S. J., Taylor L., and Howat D. J., "Empathy: A review of the concept," Emotion review, vol. 8, no. 2, pp. 144-153, 2016, doi: 10.1177/1754073914558466

[3] Kus L., Henderson L., and Batt A. M. "Empathy in paramedic practice: an overview," Journal of Paramedic Practice, vo. 11, no. 4, pp. 1-5, 2019, doi: 10.12968/jpar.2019.11.4.CPD1.

[4] Sheikh H., Carpenter J., and Wee J., "Medical student reporting of factors affecting pre-clerkship changes in empathy: a qualitative study," Canadian Medical Education Journal, vol. 4, no. 1, pp. e26-e34, 2013.

[5] Jeffrey D., "Empathy, sympathy and compassion in healthcare: Is there a problem? Is there a difference? Does it matter?," Journal of the Royal Society of Medicine, vol. 109 no.12, pp 446-452, 2016.

[6] Riess H., "The Science of Empathy," Journal of Patient Experience, vol. 4, no. 2, 74-77, 2017.

[7] Derksen F. et al., "Effectiveness of empathy in general practice: A systematic review," British Journal of General Practice, vol. 63, no. 606, pp. e76-e84, 2013.

[8] Mercer S. W. et al., "General practitioners' empathy and health outcomes: A prospective observational study of consultations in areas of high and low deprivation," Annals of Family Medicine, vol. 14, no. 2, pp. 117-124, 2016.

[9] Quince T., Thiemann P., Benson J., and Hyde S., "Undergraduate medical students; empathy: current perspectives," Advances in Medical Education and Practice, vol. 7, pp. 443-55, 2016, doi: 10.2147/AMEP.S76800.

[10] Kataoka H. et al., "Measurement of empathy among Japanese medical students: Psychometrics and score differences by gender and level of medical education," Academic Medicine vol. 84, no. 9, pp. 1192-1197, 2009.

[11] Roff S, "Reconsidering the "decline" of medical student empathy as reported in studies using the Jefferson Scale of Physician Empathy-Student version (JSPE-S)," Medical Teacher, vol. 37, no. 8, pp. 783-786, 2015.

[12] Shashikumar R. et al., "Cross sectional assessment of empathy among undergraduates from a medical college," Medical Journal Armed Forces India, vol. 70, no. 2, pp. 179-185, 2014.

[13] Listiyandini R. A. And Sulaeman D., "Empathy for Preclinical and Koas Medical Students in Jakarta (In Indonesia: Empati Mahasiswa Kedokteran Preklinik dan Koas di Jakarta)," Conference: Konferensi Nasional III Psikologi KesehatanAt: Fakultas Psikologi Universitas YARSI, vol. 1. July 2017, pp. 168-169.

[14] Jeffrey, Ian David, "Exploring Empathy with Medical Students: A Qualitative Longitudinal Phenomenology Study," Thesis, University of Edinburg, 2018.

[15] Pohontsch N. J. et al., "Influences on students'empathy in medical education: An exploratory interview study with medical students in their third and last year," BMC Medical Education, vol. 18, no. 1, pp. 1-9. 2018.

[16] Jeffrey D. and Downie R., "Empathy-Can it be taught?," Journal of the Royal College of Physicians of Edinburgh, vol. 46, no. 2, pp. 107-112, 2016, doi: 10.4997/JRCPE.2016.210.

[17] Tavakol S., Dennick R., and Tavakol, M., "Medical students' understanding of empathy: a phenomenological study," Medical Education, vol. 46, nol. 3, pp. 306-316, 2012.

[18] Eikeland $\mathrm{H}$ et al., "The physician's role and empathy-a qualitative study of third year medical students," BMC Medical Education, vol. 14, no. 1, pp. 1-8, 2014.

[19] Costa P., Magalhães E., and Costa M. J., "A latent growth model suggests that empathy of medical students does not decline over time," Advances in Health Sciences Education, vol. 18, no. 3, pp. 509-522, 2012.

[20] Ogle J., Bushnell J., and Caputi P., "Empathy is related to clinical competence in medical care," Medical Education, vol. 47, no. 8, pp. 824-831, 2013.

[21] Bellini L. M, "Variation of Mood and Empathy During Internship," JAMA, vol. 287, no. 23, pp. 3143-3146, 2021,

[22] Indonesian Medical Council, "Indonesian Doctor Competency Standards (In Indonesia: Standar Kompetensi Dokter Indonesia)," Jakarta: Konsil Kedokteran Indonesia, 2012.

[23] Arumsari D.P., Emaliyawati E., and Sriati A., "Barriers to Effective Communication of the Nurse with the Patient's Family in the Perspective of the Nurse (In Indonesia: Hambatan Komunikasi Efektif Perawat Dengan Keluarga Pasien Dalam Perspektif Perawat), ”Jurnal Pendidikan Keperawatan Indonesia, vol. 2, no. 2, p. 104-114, 2016,

[24] Rozaliyani A. et al., "Bullying in the Medical Education Environment (In Indonesia: Bullying(Perundungan) di Lingkungan Pendidikan Kedokteran), ”Jurnal Etika Kedokteran Indonesia, vol. 3, no. 2, pp. 56-60, 2019.

[25] Picard J. et al., "Burnout, empathy and their relationships: A qualitative study with residents in General Medicine," Psychology, Health and Medicine, vol. 21, no. 3, pp. 354-361, 2015.

[26] Neumann M., et al., "Empathy decline and its reasons: a systematic review of studies with medical students and residents," Academic medicine, vol. 86, no. 8, pp 996-1009, 2011.

[27] Ekman E., and Halpern J. "Professional distress and meaning in health care: Why professional empathy can help," Social work in health care, vol. 54, no. 7, pp. 633-650, 2015.

[28] Fatty Maulidira et al., "The Influence of Role Model on Career Choices in Medical Faculty Students (In Indonesia: Pengaruh Role Model terhadap Pilihan Karir pada Mahasiswa Fakultas Kedokteran)," Jurnal Pendidikan Kedokteran Indonesia, vol. 4, no. 2, pp. 75-82, 2015.

[29] Passi, V., Johnson, S., Peile, E., Wright, S., Hafferty, F., and Johnson, N., "Doctor role modelling in medical education: BEME Guide No. 27," Medical teacher, vol. 35, no. 9, pp. e1422-e1436, 2013.

[30] Putri KE, Syakurah RA, Rasyid RS, "Impact of MiniMedJob as medical career intervention program," $J E d u$ Health Promot., vol. 8, no. 205, pp. 1-5, 2019, doi: 10.4103/jehp.jehp_147_19.

[31] Ahmadian Yazdi N. et al., "The influence of role-modeling on clinical empathy of medical interns: A qualitative study," Journal of Advances in Medical Education and Professionalism, vol. 7, no. 1, pp. 35-41, 2019.

[32] Ahrweiler F. et al., "Determinants of physician empathy during medical education: hypothetical conclusions from an exploratory qualitative survey of practicing physicians," BMC Medical Education, vol. 14, no. 1, pp. 1-12, 2014.

[33] Eikeland H. L., Ørnes K., Finset A., and Pedersen R., "The physician's role and empathy-a qualitative study of third year medical students," BMC Medical Education, vol. 14, no. 1, pp. 1-8, 2014. 